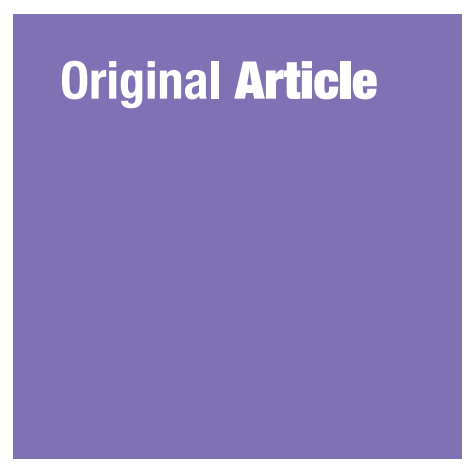

\title{
Measuring Availability, Prices and Affordability of Ischaemic Heart Disease Medicines in Bangi, Selangor, Malaysia
}

\author{
Huay Woon You, Nur Syamilah Athirah TAuUddin, Yusuf Al- \\ Mubin Shaharin Anwar
}

Pusat GENIUS@Pintar Negara, Universiti Kebangsaan Malaysia, Bangi, Selangor, Malaysia

Submitted: 3 Jun 2019

Accepted: 14 Sep 2019

Online: 4 Nov 2019

To cite this article: You HW, Tajuddin NSA, Shaharin Anwar YA-M. Measuring availability, prices and affordability of ischaemic heart disease medicines in Bangi, Selangor, Malaysia. Malays J Med Sci. 2019;26(5):113-121. https:// doi.org/10.21315/mjms2019.26.5.10

To link to this article: https://doi.org/10.21315/mjms2019.26.5.10

\begin{abstract}
Background: This study is aimed to analyse the availability, prices and affordability of medicines for ischaemic heart disease (IHD) in Bangi, Selangor, Malaysia.

Methods: A quantitative research was carried out using the methodology developed by the World Health Organization and Health Action International (WHO/HAI). The prices were compared with international reference prices (IRPs) to obtain a median price ratio. The daily wage of the lowest paid unskilled government worker was used as the standard of the affordability for the medicines. In this study, ten medicines of the IHD were included. The data were collected from 10 private medicine outlets for both originator brand (OB) and lowest-priced generic brand (LPG) in Bangi, Selangor.

Results: From the results, the mean availability of OB and LPG were $30 \%$ and $42 \%$, respectively. Final patient prices for LPG and OB were about 10.77 and 24.09 times their IRPs, respectively. Medicines that consumes more than a day's wage are considered unaffordable. Almost half of the IHD medications cost more than one day's wage. For example, the lowest paid unskilled government worker would need 1.4 days' wage for captopril, while 1.2 days' wage to purchase enalapril for LPG. Meanwhile, for $\mathrm{OB}$, the costs rise to 3.4 days' wage for amlodipine and 3.3 days' wage for simvastatin.

Conclusion: The findings of this study emphasise the need of focusing and financing, particularly in the private sector, on making chronic disease medicines accessible. This requires multi-faceted interventions, as well as the review of policies and regulations.
\end{abstract}

Keywords: ischaemic heart disease, medicine prices, affordability, availability, private sector

\section{Introduction}

In Malaysia, ischaemic heart disease (IHD) remained as the principal causes of death in 2017 (1). IHD is caused by the fatty material referred to as fatty tissue build up within the walls of arteries over time. This is often referred to as coronary-artery disease. If this build up happens within the arteries that provide the heart with blood, it is referred to as coronary cardiovascular disease. Eventually, the arteries might become slender, as the build up hinders deliverance of sufficient oxygen-rich blood to the heart, thus causing angina, which is the pain and discomfort causes by the build-up (2).

Access to a basic medical treatment is a right for human. Hence, providing access to medical care with affordable cost to patients and society has become a key health policy globally (3). However, up to $90 \%$ of the population 
in developing countries purchase medicines through out-of-pocket payments, making medicines the largest family expenditure item after food. As a result, medicines, particularly those with higher costs, may be unaffordable for large sections of the global population and are a major burden on government budgets (4).

In the past, numerous studies on medicine prices and affordability have been conducted, including IHD medicines. A study reported that four IHD medicines (aspirin, $\beta$ blockers, angiotensin-converting enzyme inhibitors (ACE), and statins) were potentially unaffordable for $0 \%-14 \%$ of households in high-income countries, $25 \%$ of upper middleincome countries, $33 \%$ of lower middle-income countries, $60 \%$ of low-income countries and $59 \%$ households in India. Moreover, patients are less likely to use all four medicines if it is not affordable to them (5).

In addition, a study performed a review of coronary artery disease in Malaysia, where it showed that Malaysians are having Acute Cardiovascular Syndrome (ACS) at a younger age compared to other developed countries, with a mean age of between 55.9 and 59.1 years compared to mean ages of between 63.4 and 68 years in most developed countries. On top of that, this study stated that the evidence continues to show that coronary artery disease is the nation's major cause of fatality and morbidity, requiring greater efforts to educate the public to change dietary habits and lifestyles, and to increase awareness of healthy living such as regular exercise (6).

It is known that patients with IHD need to take their medicines regularly to reduce the risk of getting a heart attack which could lead to a sudden death (7). Mourik et al. (8) summarised the availability, price and affordability of cardiovascular medicines from 36 countries using the World Health Organization/Health Action International (WHO/HAI) data. From the findings, there was great variability for all measures. This indicates that continuing research in this area is necessary (8). In light of this, the aim of this study is to investigate the availability, prices and affordability of IHD medicines, specifically in Bangi, Selangor, Malaysia.

The remainder of this article is structured as follows: Section 2 presents the methodology implemented in this study, Section 3 elaborates the results and discussion and finally some concluding remarks are drawn in Section 4.

\section{Materials and Methods}

This study follows the WHO/HAI methodology $(9,10)$. The minimum numbers of private medicine outlets are five for a survey area. Nevertheless, the WHO/HAI also suggested that increasing the numbers of medicine outlets above the minimum recommended numbers will increase the survey's accuracy (9). This survey was conducted in Bandar Baru Bangi, Selangor Darul Ehsan, Malaysia. The selected private sector samples should be within three hours' travel from the main public health facility. Hence, a total of 10 private medicine outlets have been selected and surveyed.

Surveys were performed according to a standardised protocol with results doubleentered into a uniform workbook for data analysis. In each survey, data on availability and patient prices were collected in a sample of private medicine outlets. Availability is expressed as the percentage of facilities where the medicine is found on the day of the data collection. Only formulations of the same strength and dosage form were included. Price is expressed as a price per unit (e.g. tablet, dose) and converted to a median price ration (MPR) by dividing the median local price by an international reference price (IRP). The IRP is obtained from the Management Sciences for Health (MSH) price indicator guide (11). The IRPs are the medians of recent procurement or tender prices offered by not-for-profit and revenue-driven suppliers to developing countries for multi-source products (12). Price ratios are not calculated when the medicine was present in less than four outlets. Whereas, treatment affordability is estimated by calculating the number of day's wage the lowest unskilled government worker needs to purchase one month's supply of medicine according to a standard treatment regimen. The size of the variation between $25^{\text {th }}$ and $75^{\text {th }}$ percentile was taken as a measure of price variation between all facilities surveyed (13).

Among 10 medicines for IHD included in the survey, three belong to the core list medicines suggested by WHO/HAI for international comparison, and seven were added as supplementary medicines (9). These were the most-surveyed medicines. The supplementary list was prepared based on the IHD needs as determined by a pilot community survey, while accounting other factors, such as the medicine utilisation patterns. All the medicines studied are listed in Table 1. For each medicine, data on 
Original Article | Availability, prices and affordability of IHD medicines

patient prices and availability were collected for both originator brand $(\mathrm{OB})$ and lowest pricedgeneric (LPG).

Table 1. List of IHD medicines

\begin{tabular}{lll} 
No. & \multicolumn{1}{c}{ Medicines } & \multicolumn{1}{c}{ Type } \\
1. & Amlodipine $10 \mathrm{mg}$ & Supplementary \\
2. & Enalapril $20 \mathrm{mg}$ & Supplementary \\
3. & Furosemide $40 \mathrm{mg}$ & Supplementary \\
4. & $\begin{array}{l}\text { Hydrochlorothiazide } 25 \\
\text { mg }\end{array}$ & Supplementary \\
5. & Lovastatin $20 \mathrm{mg}$ & Supplementary \\
6. & Nifedipine retard $10 \mathrm{mg}$ & Supplementary \\
7. & Propranolol $\mathrm{HCl} 40 \mathrm{mg}$ & Supplementary \\
8. & Atenolol $50 \mathrm{mg}$ & Global Core \\
9. & Simvastatin $20 \mathrm{mg}$ & Global Core \\
10. & Captopril $25 \mathrm{mg}$ & Global Core \\
\hline
\end{tabular}

\section{Results}

\section{Availability}

Table 2 displays the percentage availability for the 10 IHD medicines. From Table 2, availabilities of IHD medicines ranging from 0\% to $90 \%$ among the private medicine outlets in Bangi, Selangor. The mean availability of OB and LPG was $30 \%$ and $42 \%$, respectively in the private sector. Based on National Essential
Medicine List (NEML) from (14), the availability of the survey medicines listed on the NEML (excluding furosemide and lovastatin) was found with $33.75 \%$ and $42.50 \%$ for the OB and LPG, respectively.

For the OB products, amlodipine had the highest availability (i.e. 90\%), while captopril and hydrochlorothiazide were not available in the private medicine outlets samples. On the contrary, atenolol and simvastatin had the highest availability for the LPG with availability percentage of $70 \%$. Meanwhile, captopril and nifedipine retard recorded the lowest availability for $\mathrm{LPG}$, i.e. $20 \%$. Among the 10 medicines, seven LPGs had a higher availability than OB products, except amlodipine and nifedipine retard. In addition, the simvastatin had a similar percentage availability for the LPG and OB. Moreover, the mean availability of generic medicines were more than the originator brands by $12 \%$ (i.e. $42 \%-30 \%=12 \%$ ). Regardless of the brand of the medicine, analysis of all medicines availability showed that amlodipine has the highest mean availability which was $75 \%$ while captopril has the lowest mean availability among the private sector which was just $10 \%$.

Table 3 lists the availability of individual medicines in the private medicine outlets. Only eight OBs and 10 LPGs were found in the private sector with only $36 \%$ availability as a whole, based on Table 2, which is quite low for IHD patients as this is the main killer disease in Malaysia. 
Table 2. Percentage availability for the 10 IHD medicines

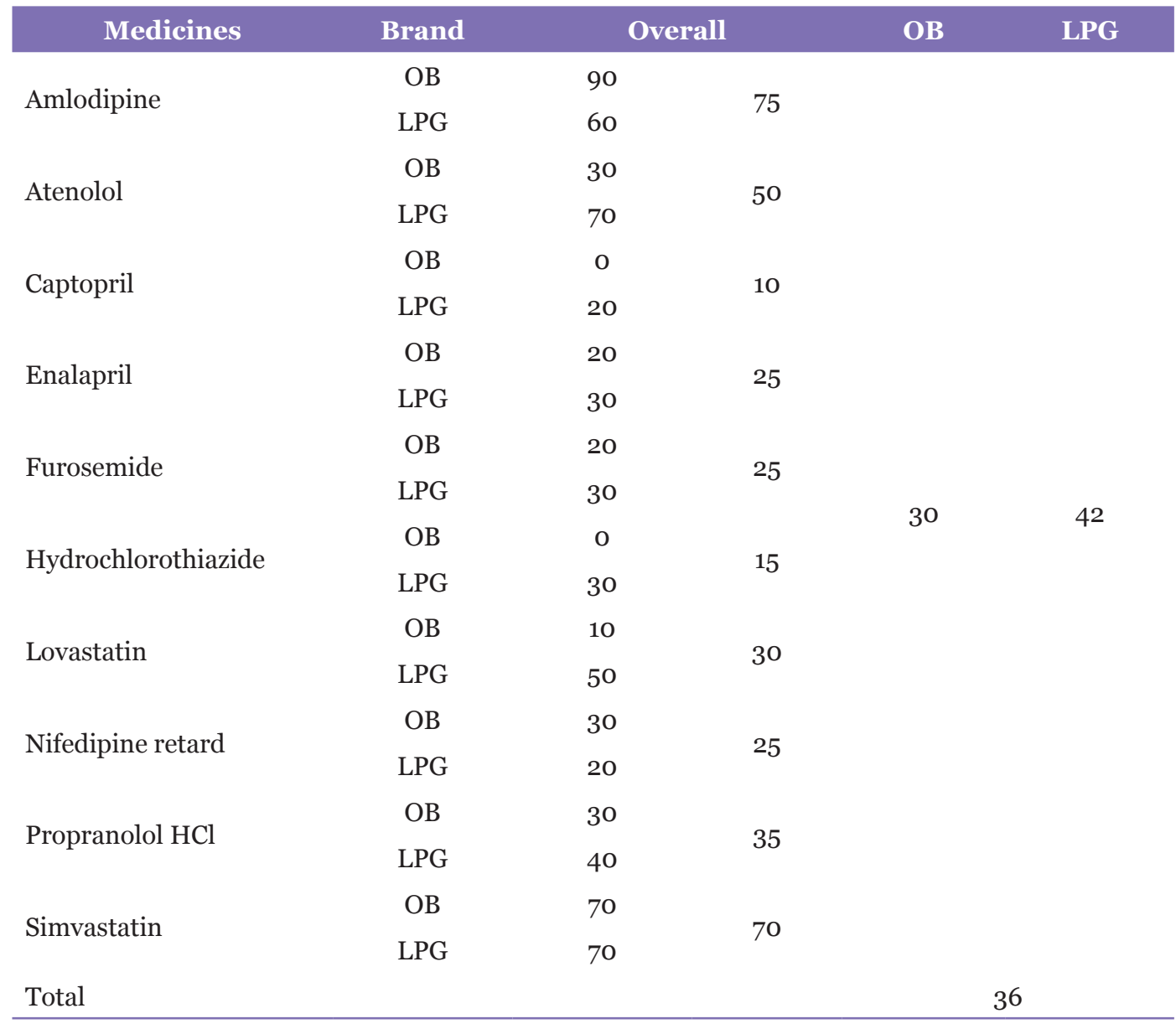

Table 3. Availability of medicines in the private medicine outlets

\begin{tabular}{lll}
\multicolumn{1}{c}{ Availability } & \multicolumn{1}{c}{ Originator brand } & \multicolumn{1}{c}{ Lowest-priced generic } \\
$\begin{array}{l}\text { Medicines not found in any outlets } \\
\begin{array}{l}\text { Medicines found in less than 25\% of } \\
\text { outlets }\end{array}\end{array}$ & $\begin{array}{l}\text { Captopril, Hydrochlorothiazide } \\
\text { Enalapril, Furosemide, Lovastatin }\end{array}$ & $\begin{array}{l}\text { Captopril, Nifedipine retard } \\
\begin{array}{l}\text { Medicines found in 25\% to 50\% of } \\
\text { outlets }\end{array}\end{array}$ \\
$\begin{array}{l}\text { Atenolol, Nifedipine retard, } \\
\text { Propranolol HCl }\end{array}$ & $\begin{array}{l}\text { Enalapril, Furosemide, } \\
\text { Hydrochlorothiazide, Lovastatin, } \\
\text { Putlets }\end{array}$ & $\begin{array}{l}\text { Propranolol HCl } \\
\text { Amlodipine, Atenolol, Simvastatin }\end{array}$ \\
$\begin{array}{l}\text { Medicines found in over 75\% of } \\
\text { outlets }\end{array}$ & Amlodipine & \\
\hline
\end{tabular}


Original Article | Availability, prices and affordability of IHD medicines

\section{Median Price Ratios and Medicine Prices Variation}

Table 4 summarises the MPR for the 10 IHD medicines, which ranged from 11.99 for simvastatin to 46.64 for lovastatin for $\mathrm{OB}$ and from 2.02 for simvastatin to 31.10 for lovastatin for LPG. Across the IHD medicines, the highest MPR was found in lovastatin (OB) with 46.64, while the lowest MPR, 2.02, was found in simvastatin (LPG).

Overall, based on Table 4, the private sector procured 10 generics at 10.77 times their IRPs and eight OBs at 24.0 times their IRPs. The MPRs of eight OBs-amlodipine [17.99], atenolol [22.90], enalapril [14.33], furosemide [40.84], lovastatin [46.64], nifedipine retard [15.58], propranolol [22.46] and simvastatin [11.99] were more than 10 times their IRPs. Ten LPGs were procured at higher prices than the IRPs; six medicines were more than five times the reference price, including captopril [10.76], enalapril [20.91], furosemide [11.72], lovastatin [31.10], hydrochlorothiazide [8.87] and propranolol [10.37].

Further analysis of 10 medicines for which OBs and generically equivalent products showed that in the private sector, OB cost $63.63 \%$ more, on average, than their generic equivalents. Thus, patients pay substantially more for originator brand medicines when lower-cost generics are unavailable.

Low variation across all the medicines was noted for both OB and LPG medicines in the private sector. Based on Table 4, the overall price variation for OBs was 1.74 while for LPGs was 1.49. Hence, price variation for OBs was higher than LPGs in this study by $14.4 \%$.

Table 4. Median price ratio (MPR) of OBs and LPGs in the private sector

\begin{tabular}{|c|c|c|c|c|c|}
\hline Medicine name & Brand & $\begin{array}{c}\text { Median } \\
\text { price ratio }\end{array}$ & $\begin{array}{c}\text { Price } \\
\text { variation } \\
(\mathbf{Q 7 5} / \mathbf{Q 2 5})\end{array}$ & $\begin{array}{l}\text { Minimum } \\
\text { price }\end{array}$ & $\begin{array}{c}\text { Maximum } \\
\text { price }\end{array}$ \\
\hline \multirow[t]{2}{*}{ Amlodipine } & Brand & 17.99 & 1.33 & 6.43 & 34.70 \\
\hline & Lowest price & 4.02 & 1.41 & 2.89 & 6.36 \\
\hline \multirow[t]{2}{*}{ Atenolol } & Brand & 22.90 & 1.99 & 6.70 & 36.03 \\
\hline & Lowest price & 4.69 & 1.32 & 3.75 & 21.43 \\
\hline \multirow[t]{2}{*}{ Captopril } & Brand & - & - & - & - \\
\hline & Lowest price & 10.76 & 1.30 & 7.95 & 13.57 \\
\hline \multirow[t]{2}{*}{ Enalapril } & Brand & 14.33 & 1.60 & 7.74 & 20.91 \\
\hline & Lowest price & 20.91 & 1.13 & 16.73 & 21.54 \\
\hline \multirow[t]{2}{*}{ Furosemide } & Brand & 40.84 & 1.40 & 27.363 & 54.33 \\
\hline & Lowest price & 11.72 & 1.09 & 9.77 & 11.72 \\
\hline \multirow[t]{2}{*}{ Hydrochlorothiazide } & Brand & - & - & - & - \\
\hline & Lowest price & 8.87 & 1.39 & 8.32 & 14.97 \\
\hline \multirow[t]{2}{*}{ Lovastatin } & Brand & 46.64 & 1.00 & 46.64 & 46.64 \\
\hline & Lowest price & 31.10 & 1.30 & 21.77 & 67.38 \\
\hline \multirow[t]{2}{*}{ Nifedipine retard } & Brand & $15 \cdot 58$ & 1.39 & 9.34 & 19.17 \\
\hline & Lowest price & 3.23 & 1.77 & 1.44 & 5.03 \\
\hline \multirow[t]{2}{*}{ Propranolol $\mathrm{HCl}$} & Brand & 22.46 & 1.17 & 17.28 & 24.19 \\
\hline & Lowest price & 10.37 & 3.00 & 3.46 & 31.10 \\
\hline \multirow[t]{2}{*}{ Simvastatin } & Brand & 11.99 & 4.04 & 2.02 & 20.65 \\
\hline & Lowest price & 2.02 & 1.14 & 1.57 & 3.59 \\
\hline
\end{tabular}




\section{Affordability}

The affordability of treatments for IHD medicines are given in Table 5. In general, OB products were less affordable than the LPG equivalents in the private sector. The affordability of LPGs in the private sector had reasonable affordability (with standard treatment costing a day's wage or less) for nearly all LPGs medicines. The exception for this were captopril and enalapril. The most affordable standard treatment was hydrochlorothiazide with 0.2 days' wage to purchase one month of treatment. When OBs are prescribed and dispensed in the private sector, some treatment costs much higher than the LPGs. For example, treating IHD with $\mathrm{OB}$ of amlodipine required 3.4 days' wage while LPG of amlodipine only required 0.8 days' wage.

Figure 1 summarises the availability and price of IHD medicines in the 10 private medicine outlets. The percentage availability for each medicine is depicted on the $x$-axis, while the $y$-axis shows the value of MPR.
The figure can be divided to four quadrants. Quadrant IV contains medicines with low MPR and high availability, for example simvastatin (OB) which has $70 \%$ availability and a MPR of 11.99. Quadrant I contains medicines with high MPR and low accessibility. Patients face high financial burden and trouble in getting them. For example, lovastatin (OB) was available in only $10 \%$ of surveyed private sectors and cost over 46.64 times the IRP. Hence, lovastatin (OB), furosemide (OB), propranolol (OB), atenolol (OB), and enalapril (LPG) making IHD treatment potentially challenging in Bangi, Selangor.

Notably, some generics are easily accessed at low cost in the private sectors, such as amlodipine (supplementary), atenolol (global core) and simvastatin (global core). This can be concluded that Bangi, Malaysia is in the right path in maintaining the usage of global core medicines for IHD as two out of three surveyed global core medicines have high availability in the study area.

Table 5. Treatment affordability for 10 IHD medicines

\begin{tabular}{|c|c|c|c|c|c|}
\hline Medicines & $\begin{array}{c}\text { Medicine } \\
\text { strength (mg) }\end{array}$ & Dosage form & $\begin{array}{c}\text { Treatment } \\
\text { duration (days) }\end{array}$ & Brand & $\begin{array}{l}\text { Days' } \\
\text { wage* }^{*}\end{array}$ \\
\hline \multirow{2}{*}{ Amlodipine } & \multirow{2}{*}{10} & \multirow{2}{*}{ Cap/tab } & \multirow{2}{*}{30} & OB & 3.4 \\
\hline & & & & LPG & 0.8 \\
\hline \multirow{2}{*}{ Atenolol } & \multirow{2}{*}{50} & \multirow{2}{*}{$\mathrm{Cap} / \mathrm{tab}$} & \multirow{2}{*}{30} & $\mathrm{OB}$ & 2.1 \\
\hline & & & & LPG & 0.4 \\
\hline \multirow{2}{*}{ Captopril } & \multirow{2}{*}{25} & \multirow{2}{*}{$\mathrm{Cap} / \mathrm{tab}$} & \multirow{2}{*}{30} & OB & - \\
\hline & & & & LPG & 1.4 \\
\hline \multirow{2}{*}{ Enalapril } & \multirow{2}{*}{20} & \multirow{2}{*}{$\mathrm{Cap} / \mathrm{tab}$} & \multirow{2}{*}{30} & $\mathrm{OB}$ & 0.8 \\
\hline & & & & LPG & 1.2 \\
\hline \multirow{2}{*}{ Furosemide } & \multirow{2}{*}{40} & \multirow{2}{*}{$\mathrm{Cap} / \mathrm{tab}$} & \multirow{2}{*}{30} & OB & 1.3 \\
\hline & & & & LPG & 0.4 \\
\hline \multirow{2}{*}{$\begin{array}{l}\text { Hydrochlorothiazide } \\
\text { (HCTZ) }\end{array}$} & \multirow{2}{*}{25} & \multirow{2}{*}{$\mathrm{Cap} / \mathrm{tab}$} & \multirow{2}{*}{30} & OB & - \\
\hline & & & & LPG & 0.2 \\
\hline \multirow{2}{*}{ Lovastatin } & \multirow{2}{*}{20} & \multirow{2}{*}{$\mathrm{Cap} / \mathrm{tab}$} & \multirow{2}{*}{30} & OB & 1.1 \\
\hline & & & & LPG & 0.7 \\
\hline \multirow{2}{*}{ Nifedipine retard } & \multirow{2}{*}{10} & \multirow{2}{*}{$\mathrm{Cap} / \mathrm{tab}$} & \multirow{2}{*}{30} & OB & 2.7 \\
\hline & & & & LPG & 0.6 \\
\hline \multirow{2}{*}{ Propranolol $\mathrm{HCl}$} & \multirow{2}{*}{40} & \multirow{2}{*}{$\mathrm{Cap} / \mathrm{tab}$} & \multirow{2}{*}{30} & $\mathrm{OB}$ & 0.8 \\
\hline & & & & LPG & 0.4 \\
\hline Simvastatin & 20 & $\mathrm{Cap} / \mathrm{tab}$ & 30 & OB & 3.3 \\
\hline & & & & LPG & 0.6 \\
\hline
\end{tabular}


Original Article | Availability, prices and affordability of IHD medicines

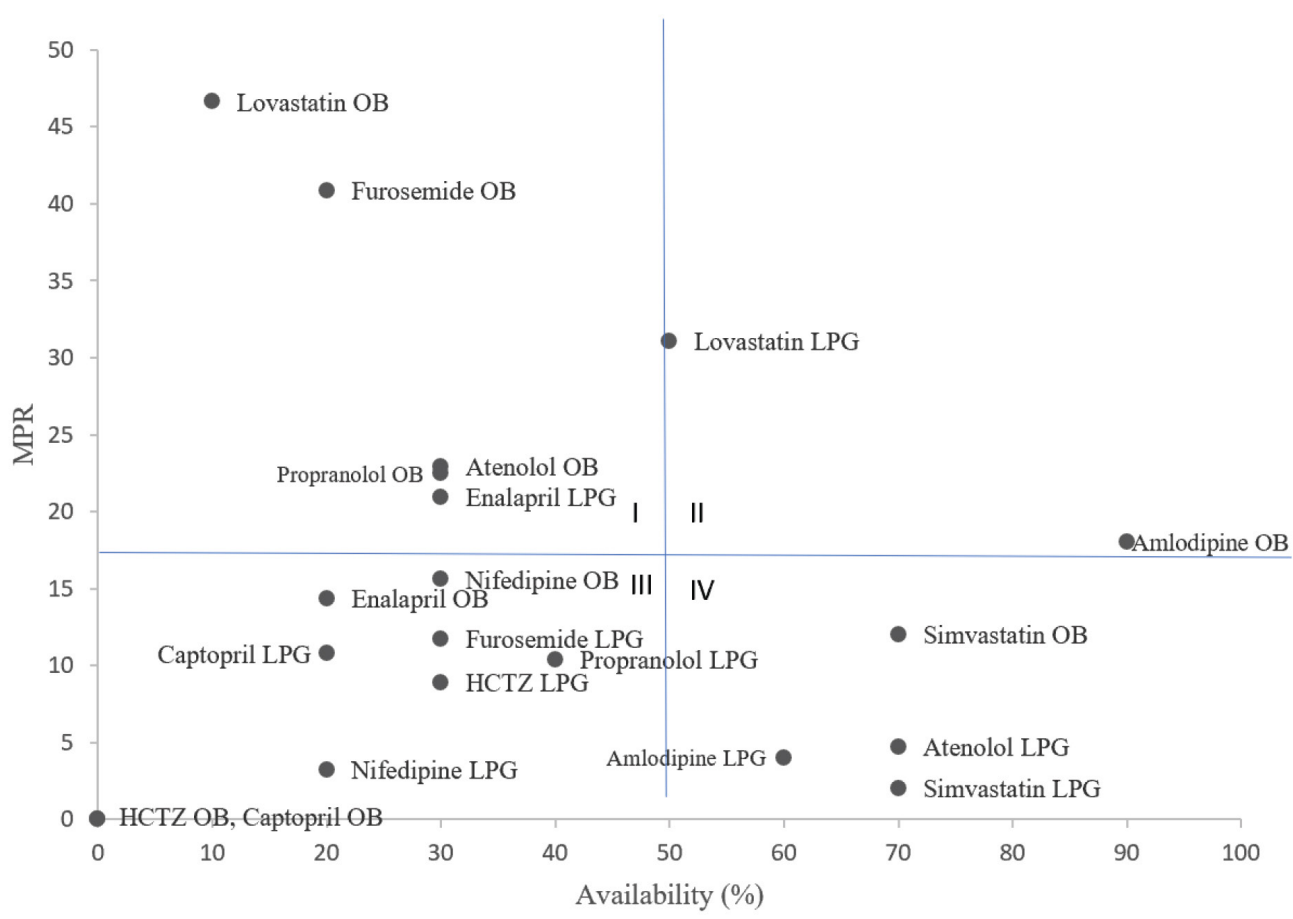

Figure 1. Medicine availability and MPR for OBs and LPGs

\section{Discussion}

Availability of medicines is important for patients' access to treatment. The average availability of medicines in Bangi, Malaysia was $36 \%$ in the private sector. However, availabilities of over $50 \%$ were observed in some medicines (OB and/or LPG). This study also found that the availability of LPG was higher than originators in the private sector which reflects the country's Generic Medicines Policy. Since Malaysian National Medicines Policy (MNMP) was endorsed by the Malaysian Cabinet in 2006, generic medicines have been widely used in the public sector, which influence the private sector too. This is one of the government's initiative to promote the use of generics in the community (15).

The highest price variation goes to simvastatin (OB) with 4.04 and propranolol $\mathrm{HCl}$ (LPG) with 3.00 (see Table 4). This shows that the variation of prices for simvastatin and propranolol $\mathrm{HCl}$ were high across different medicine outlets, which means that the gap between the prices varied distinctively. Aside from that, the rest of the medicines have low price variation which were near to 1.oo. Thus, the price variation for the IHD medicines was generally low according to this study. This result reflected that medicine outlets in Bangi follow the market price recommended by the supplier.

The patient prices of originators were fairly stable across private premises as there was only a single brand for each medicine in the market. Previous works in Malaysia demonstrated that prices of originators indirectly serve as a cap to generics as the latter are still relatively affordable even after significant mark-ups (16). Nevertheless, the Good Pharmaceutical Trade Practice (GPTP) guideline was published by the (15) to promote standard price and bonus scheme to all distribution channels and health care providers. This rule received additional support from the Malaysia Competition Commission (MyCC), though it is not legitimately authoritative. Therefore, adherence is poor as execution by pharmaceutical organisations is purely voluntary. Hence, combined with competition among various generic brands for each medicine in the market, this study may clarify the patient price variations across generics observed in this study.

According to (9), treatments that needs less than a day's wage are considered affordable. In relation to this, some medicines in this study were affordable, such as amlodipine (LPG), atenolol (LPG), enalapril (OB), furosemide (LPG), hydrochlorothiazide (LPG), lovastatin 
(LPG), nifedipine retard (LPG), propranolol $\mathrm{HCl}$ (OB and LPG), and simvastatin (LPG) based on Table 5. Generally, the LPG were more affordable. This can be supported with the results of this study which shows that only two OBs were affordable (enalapril, 0.8 days' and propranolol $\mathrm{HCl}$, 0.8 days'), while two LPGs were not affordable (captopril, 1.4 days' and enalapril 1.2 days'). This indicates that OBs were less affordable for chronic disease medicines in the private sector. These results are in line with previous studies, see (17-19), to name a few. Although the low-income population may utilise the public health care, there is still a proportion of the population that visit the private sector and may not be able to afford continuous treatment (13).

\section{Conclusion}

This analysis demonstrates that the average availability of IHD medicines was $36 \%$ in private medicine outlets, in which the LPGs were higher than OB products. For the affordability of treatments, the medicines are classified as affordable when it requires less than a day's wage of the lowest paid unskilled government worker. From the findings, nearly all the LPG medicines are affordable. However, despite the affordability of generic medicines, certain innovator medicines are unaffordable (amlodipine, atenolol, furosemide, lovastatin, nifedipine retard, simvastatin). Further, prices of medicines which procured much higher than the IRPs should be reviewed, for example, Lovastatin (OB and LPG) and Furosemide (OB). As with patient prices, the availability varied among the IHD medicines.

Looking at these results, future research works can be extended to include the public sector and compare the availability, prices and affordability between private and public sectors in Bangi, Selangor, Malaysia. Besides, future studies are also recommended for other chronic disease medicines, such as pneumonia.

\section{Acknowledgements}

The authors would like to convey appreciation to all private medicine outlets in giving invaluable responses in this study.

\section{Conflict of Interest}

None.

\section{Funds}

None.

\section{Authors' Contributions}

Conception and design: YHW, NSAT, YA-MSA

Analysis and interpretation of the data: YHW, NSAT, YA-MSA

Drafting of the article: YHW, NSAT, YA-MSA

Critical revision of the article for important intellectual content: YHW, NSAT, YA-MSA

\section{Correspondence}

\section{Dr You Huay Woon}

$\mathrm{PhD}$ (Universiti Sains Malaysia)

Pusat GENIUS@Pintar Negara,

Universiti Kebangsaan Malaysia, 43600 Bangi, Selangor, Malaysia.

Tel: +60176069458

Fax: +603 89217525

E-mail: hwyou@ukm.edu.my

\section{References}

1. Department of Statistics Malaysia. Press release: statistic on causes of death, Malaysia, 2018; 2018. [Retrieved 2019 June 3]. Available from: https://www.dosm.gov.my/v1/index. php?r=column/pdfPrev\&id=aWg2VjJkZHhYcDd EM3JQSGloeTVlZzo9

2. British Heart Foundation. Coronary heart disease (also known as ischaemic heart disease); n.d. [Retrieved 2019 June 3]. Available from: https:// www.bhf.org.uk/informationsupport/conditions/ coronary-heart-disease

3. Aaltonen K. Affordability of medicines from the pharmaceutical system perspective: Comparative analysis of Finland and New Zealand. Kela, Helsinki: Studies in Social Security and Health; 2017.

4. World Health Organization. WHO guideline on country pharmaceutical pricing policies; 2015. [Retrieved 2019 June 3]. Available from: http://apps.who.int/medicinedocs/documents/ s21016en/s21016en.pdf 
Original Article | Availability, prices and affordability of IHD medicines

5. Khatib R, McKee M, Shannon H, Chow C, Rangarajan S, Teo K, et al. Availability and affordability of cardiovascular disease medicines and their effect on use in highincome, middle-income, and low-income countries: an analysis of the PURE study data. Lancet. 2015;387(10013):61-69. https://doi. org/10.1016/So140-6736(15)00469-9

6. Ang CS, Chan JKM. A review of coronary artery disease research in malaysia. Med $J$ Malays. 2016;71(Supplement 1):42-57.

7. Lim BC, Kueh YC, Arifin WN, Ng KH. Psychometric properties of the heart disease knowledge scale: Evidence from item and confirmatory factor analyses. Malays $\mathrm{J} \mathrm{Med} \mathrm{Sci.}$ 2016;23(4):33-45. https://doi.org/10.21315/ mjms2016.23.4.5

8. Mourik M, Cameron A, Ewen M, Laing RO. Availability, price and affordability of cardiovascular medicines: A comparison across 36 countries using WHO/HAI data. BMC Cardiovasc Disord. 2010;25(10):1-9. https:// doi.org/10.1186/1471-2261-10-25

9. World Health Organization and Health Action International. Measuring medicine prices, availability, affordability and price components. 2nd ed. Switzerland:WHO; 2008. [Retrieved 2019 June 3]. Available from: https://www.who.int/ medicines/areas/access/OMS_Medicine_prices. pdf

10. World Health Organization and Health Action International. Measuring medicine prices, affordability, availability and price components; 2016. [Retrieved 2019 June 3]. Available from: http://haiweb.org/wp-content/uploads/2016/o6/ Workbook-Part-1.xls

11. Management Sciences for Health (MSH). International drug price indicator guide, 2014 ed. Medford, Mass, USA: MSH; 2015. [Retrieved 2019 June 3]. Available from: http://apps. who.int/medicinedocs/documents/s21982en/ s21982en.pdf

12. McFadyen MA, Cannella AA. Social capital and knowledge creation: diminishing returns of the number and strength of exchange relationships. Acad Manag J. 2004;47(5):735-746. https:// doi.org/10.2307/20159615
13. Ministry of Health Malaysia. Medicine Prices monitoring in Malaysia: survey report 2017. Kuala Lumpur, Malaysia: Pharmaceutical Services Programme, Ministry of Health Malaysia; 2018 [Retrieved 2019 June 3]. Available from: https:// www.pharmacy.gov.my/v2/sites/default/files/ document-upload/medicine-price-monitoringmalaysia-2017-final-sep-18.pdf

14. Ministry of Health Malaysia. National essential medicines list, 4th ed. Kuala Lumpur, Malaysia: Pharmaceutical Services Division, Ministry of Health Malaysia; 2012. Available from: https:// www.pharmacy.gov.my/v2/en/documents/ national-essential-medicine-list-neml.html

15. Ministry of Health Malaysia. Pharmacy programme annual report 2014. Kuala Lumpur: Malaysia: Pharmaceutical Services Division, Ministry of Health Malaysia; 2015. [Retrieved 2019 June 3]. Available from: http://www. pharmacy.gov.my/v2/sites/default/files/ document-upload/ar-pharmacy-2014-final_1.pdf

16. Babar ZUD, Ibrahim MIM, Singh H, Bukahri NI, Creese A. Evaluating drug prices, availability, affordability and price components: implications for access to drugs in Malaysia. PLoS Med. 2007;4(3):466-475. https://doi.org/10.1371/ journal.pmed.0040082

17. Ahmad NS, Islahudin F. Affordability of essential medicine prices in Malaysia's private health sector. Patient Prefer Adherence. 2018;12:12311237. https://doi.org/10.2147/PPA.S151603

18. Zaprutko T, Kopciuch D, Kus K, Merks P, Nowicka M, Augustyniak I, et al. Affordability of medicines in the European Union. PLoS One. 2017;12(2):e0172753. https://doi.org/10.1371/ journal.pone.0172753

19. Mhlanga BS, Suleman F. Price, availability and affordability of medicines. Afr $J$ Prim Health C Fam Med. 2014;6(1):E1-E6. https://doi. org/10.4102/phcfm.v6i1.604 